psychotherapy practitioners of the future deserve to be taught and supervised by people having a full range of relevant skills.

The only sad note in this useful, enjoyable meeting was the saying goodbye to Sidney Bloch. He has played a leading part in the organisation of this AUTP meeting together with Mark Aveline (and on this occasion joined by Stuart Liberman and Bernie Rosen) as well as having been productive in so many other ways. $\mathrm{He}$ is due to leave these shores for
Melbourne at the end of the year and took with him the warmest good wishes of all those at the meeting.

\section{References}

${ }^{1}$ CAWLEY, R. H. (1977) The teaching of psychotherapy. Association of University Teachers of Psychiatry Newsletter. January, 19-36.

${ }^{2}$ MACASKILl, N. (1988) Personal therapy in the training of the psychotherapist: Is it effective? British Journal of Psychotherapy, 4, 219-226.

\title{
Management and comprehensive psychiatry
}

\author{
Ian B. Cookson, Consultant Psychiatrist, Sefton General Hospital, Liverpool
}

4 November 1987 saw a multi-professional one day symposium in the North West Division A Comprehensive Psychiatry Service: Norms, Resources, Boundaries and Problems. Sponsored by Lundbeck Limited, over a hundred managers, psychiatrists, nurses and paramedical professionals attended.

Lack of leadership by psychiatrists reluctant to identify their skills and subject them to indices of efficiency was identified. They should acquire managerial skills, said Dr Digby Tantam.

Making perhaps the most important contribution of the day, Professor Steven Hirsch stated that indices of social deprivation correlate with psychiatric morbidity and should be the basis of service planning, as the College working party he chaired had recently concluded.

Professor Anthony Cox led a group of clinicians who described problems of under-provision, such as the $50 \%$ shortfall of College norms which child and adolescent psychiatry suffers. Mental handicap had too few beds but Dr Valerie Anness was content not to lead the team, whose main function was nonmedical. Treatment of alcohol, drug, and psychosexual problems were areas limited by resources, as conspicuously, was psychotherapy.

Major requirements for intensive nursing in a structured environment, linking forensic and NHS provision, and absence of resources for the brain damaged and presenile dementia patients were also described.

The general adult psychiatrists' contribution as the major manpower input in clinical work was presented by Dr Sidney Levine. Much of the demand on time was, however, other than clinical.
Following lunch, Dr Douglas Bennett emphasised priority for those chronic patients with low social, medical and political status. Work with these individuals, their families and provision of occupation is neglected, he said. Shelter, support and avoidance of transinstitutionalisation on closure of psychiatric hospitals might be achieved with supervision of continuing care.

Dr Keith Bridges presented an evaluation of Douglas House, a hostel-ward in the community run by the University of Manchester Department of Psychiatry. He concluded that a spectrum of facilities are required in the community. The hostel-ward was cost-effective for those it served; only a few patients returned to hospital.

Managers Drs Baigal and Tunstall for the North West and Mersey Regional Health Authorities acknowledged the need for morbidity linked planning and performance indicator measurements of efficiency. Psychiatry funds were protected, we were assured.

Much interested discussion revealed anxieties on funding, lack of influence of psychiatrists in planning and, as Professor Hugh Freeman pointed out, the wholesale removal of social workers from the Maudsley Hospital showed the failure of collaboration with some social service departments. Voluntary organisations had an important contribution to community care.

The two chairmen of the day, Dr Donald Johnson and Dr David Enoch, concluded that the rush to close psychiatric hospitals without pilot studies and quality control of the emerging services, the failure to emphasise the role of chemotherapy in treatment and 
the absence of psychiatrists from management would prejudice development of the future service which requires a flexible spectrum of treatment and care settings, delivered by caring well trained multidisciplinary staff. Managers expressed a desire for further meetings of this kind.

In a lunchtime discussion with Dr Lissmore of the DHSS at the College Social and Community Section meeting in Spring 1987, he described a management model which would likely be effective in planning, delivery, researching and monitoring comprehensive psychiatry services. A functional psychiatry unit would have an executive of its Unit General Manager, a Unit Medical Representative, the District Nursing Chief (for residential and community psychiatric nursing), and a paramedical staff representative. The medical and paramedical representatives of the Executive would be elected by their respective professional groups.

The Executive would report by their presence to a monthly multi-professional 'legislative' meeting of the whole body of consultant psychiatrists, the nursing chief, and the heads of paramedical professions or their psychiatry sections. The Unit General Manager with selected staff, e.g. the Care in the Community Co-ordinator, would be members of this body.

This policy-making advisory committee for the district's comprehensive psychiatry service would also receive minutes of the meetings of specialty advisory groups, care delivery teams, and project meetings convened at times to pursue policy and planning of such service components as day facilities, chronic patient care, and, for example, to consider teaching and training requirements.

Adoption of such a management and advice giving structure would avoid many difficulties of communication, and sharing of information and philosophy may promote rather than constrain the development of services for those for whom we care.

The threat of chronic patient care being given to local authorities and its possible funding by local taxation should be discussed locally and nationally and protest made through whatever structures exist at present. In the Mersey Regional Health Authority we have seen psychiatrists impotent to prevent, with or without their advice being sought, problems such as bed closures, patient movements within hospitals from ward to ward, for administrative reasons the removal from a department of psychiatry to primary care of a community psychiatric nursing service, gross underfunding of new DGH services, loss of resources for psychiatry and ensure the minimum requirements for the establishment of posts for psychogeriatric appointments, among many others.

Leadership by the consultant psychiatrists must be shown to be advantageous to our present management for our patients' future to be protected.

A further meeting in the North West Division in the autumn will pursue these matters but diplomatic and wise action now, informally and formally, should be pursued to regain influence, if only in damage limitation for psychiatrists.

\section{Comment}

\section{'Facts and Figures' and 'Reviewing the Regional Plans'}

These two short documents from the National Schizophrenia Fellowship (NSF News, February 1988) provide a wealth of useful information.

The facts and figures refer to the 1987 edition of the DHSS Health and Personal Social Services Statistics for England. During the period mainly covered, from 1975 to 1985 , the number of occupied mental illness beds fell from 87,000 to 65,000 . This still represents $25 \%$ of all occupied hospital beds, although mentally ill patients comprise only $4 \%$ of total admissions. The number of psychiatric hospitals and units in contrast increased, both in total and as a proportion of all hospitals. They have of course become smaller; nonetheless, in $198555 \%$ of psychiatric in-patients were in hospitals with more than 500 beds.

The 1985 average cost of a person with mental illness in hospital was approximately $£ 14,000$ per year. The cost of mental illness services as a proportion of the total hospital budget is described as having 'only' dropped from $12.7 \%$ to $11.1 \%-834$ million out of 7.5 billion pounds: but the much more rapid turnover inevitably increases costs despite the reduction in beds.

The total number of admissions increased from 175,000 in 1975 to nearly 200,000 ten years later. The percentage of the population being admitted 